\title{
Obesity and Endometrial Cancer: Increase in Frequency over a Period of 44 Years
}

\author{
Alfonso Torres Lobaton ${ }^{1, ~ *, ~ R o s a l v a ~ B a r r a ~ M a r t i n e z ~}{ }^{1}$, Elisa Paola Jimenez Arroyo ${ }^{1}$, \\ Juan Carlos Oliva Posada ${ }^{1}$, Carla America Suarez Juarez ${ }^{2}$, Fred Morgan Ortiz ${ }^{3}$ \\ ${ }^{1}$ Oncology Unit, General Hospital of Mexico, Mexico City, Mexico \\ ${ }^{2}$ Diamond Tower, Metropolitan Angel's Hospital, Mexico City, Mexico \\ ${ }^{3}$ Research Center in Health Sciences, Autonomous University of Sinaloa, Mexico City, Mexico
}

Email address:

drtorreslobaton44@gmail.com (A. T. Lobaton), rossbar13@yahoo.com.mx (R. B. Martinez), paolajimenezarroyo@gmail.com (E. P. J. Arroyo), skallo.onco@gmail.com (J. C. O. Posada), dra.america.suarez@gmail.com (C.A. S. Juarez),fmorganortiz@uas.edu.mx (F. M. Ortiz)

*Corresponding author

\section{To cite this article:}

Alfonso Torres Lobaton, Rosalva Barra Martinez, Elisa Paola Jimenez Arroyo, Juan Carlos Oliva Posada, Carla America Suarez Juarez, Fred Morgan Ortiz. Obesity and Endometrial Cancer: Increase in Frequency over a Period of 44 Years. Journal of Gynecology and Obstetrics.

Vol. 8, No. 6, 2020, pp. 161-165. doi: 10.11648/j.jgo.20200806.12

Received: October 7, 2020; Accepted: October 19, 2020; Published: October 30, 2020

\begin{abstract}
To draw attention to the increase in the frequency of endometrial cancer (CE) in recent decades and its association with overweight and obesity in a highly specialized institution. Retrospective study of patients with EC treated in the Oncology Service (OS) General Hospital of Mexico (GHM), in the years 2000 to 2017, obtaining information related to some risk factors and their classification. The data were compared with a previous study from the years 1966-1993. Of the record of 1,045 EC treated during the studied time of 44 years, 785 corresponded to the period 2000-2017 and 260 to the previous report, which meant an increase of $200 \%$ for this disease. Of gynecological cancers, the EC figures increased from $17.9 \%$ in $2010-2011$ to $29.4 \%$ in 2016-2017 ( $\mathrm{p}=0.0001)$. Overweight and obesity were in 572/785 (72.8\%) of the current series vs. 120/260 (46.1\%) of the previous series $(\mathrm{p}<0.05)$. An increase of $19 \%$ to $28 \%$ was found in women younger than 48 years when comparing the periods 2000 - 2009 vs. $2010-2017$ ( $\mathrm{p}=0.011$ ); 119/389 classified as stage I, (30.5\%) had risk factors for tumor recurrence and $378 / 898(42.0 \%)$ had advanced malignancies. An increase in CE reported in this series and its association with overweight and obesity, may highlight the public health problem that this association represents in our country.
\end{abstract}

Keywords: Obesity, Endometrial, Cancer, Increase, Frequency

\section{Background}

Endometrial cancer (CE) is the first gynecological neoplasm diagnosed in developed countries [1,2]. The World Health Organization (WHO) registered in 2018 in Mexico a frequency of $\mathrm{CE}$ of 7,266 cases, so it is the second gynecological malignancy just below cervical cancer [3]. This was the first time in our country that EC replaced the epithelial ovarian cancer (EOC) that had occupied this place until then, according to the Epidemiology Directorate of the Ministry of Health [4].

It has been established that overweight and obesity are closely linked to the development of EC $[5,6]$. The metabolic and endocrinological effects of menopause such as high levels of estrogens resulting from the conversion of androstenedione to estrone, the aromatization of androgens to estrogens in peripheral adipose tissue and high insulin levels [6]. However, many unresolved questions arise from the interaction between obesity, estrogens, and insulin as mediators of endometrial carcinogenesis [6,7].

The National Institute of Public Health in Mexico published in 2018 that the prevalence of overweight and obesity has increased in the last 3 decades, making it one of the two countries with the highest prevalence of obesity in the world [8]. In adults aged 20 years and 78 over, the prevalence of overweight and obesity in 2016 was $72.5 \%$ 
and, according to the National Survey of Health and Nutrition (NSHN) this percentage increased to $74.9 \%$ in 2018 [9].

This article shows the frequency and increase in recent decades of EC in the General Hospital of Mexico (MGH) and its relationship with the rest of gynecological cancers over time. We attribute it to its association with overweight and the obesity.

\section{Material and Methods}

Retrospective and observational study in patients with a histopathological diagnosis of EC treated at the MGH during the years 2000 to 2017 , obtaining risk factors for EC such as age, overweight and obesity, hypertension and diabetes. The cases were classified according to the Clinical Stage (CS) of the International Federation of Gynecology and Obstetrics (FIGO) in its 2009 version [1, 10, 11].

We compared the frequency of EC in three time periods, the first from 1983-1984 [12], the second from 2010-2011 [13] and finally from 2016-2017. The results obtained in terms of risk factors and CE from the period 2000 to 2017 were compared with the data recorded for the period 19661993 [14]. A body mass index (BMI) of 25-29.9 was considered overweight and a BMI of $30.0-50$ obesity $[6,9]$. For statistical analysis we use the Epi-info v 7 system and the Chi square test. Confidence values of less than $95 \%$ were specific without statistical significance (N. S.).

Results: In this study we registered a total of 1,045 patients with $\mathrm{CE}$ in a 44-year period, of these, 785 cases corresponded to the time period between 2000 and 2017. In a first period of 27 years, we treated 260 patients, while in the last 17 years a total of 785 patients, which meant a $200 \%$ increase in the frequency of this disease Table 1.

The analysis of the relative frequency of gynecological cancers in 3 different variables, selected when comparing the periods 2010-2011 vs. 2016-2017; an increase in EC figures from $17.9 \%$ to $29.4 \%$. $(\mathrm{p}=0001)$, data that place it in second place among gynecological cancers of the Oncology Unit Table 2.

When comparing the risk factors analyzed for EC, for the $1966-1993$ vs $2000-2017$ intervals, an increase from $46.1 \%$ to $72.5 \%(p=<05)$ was found in terms of overweight and obesity; of hypertension from 30 to $33 \%(\mathrm{p}=0.412)$ and diabetes from $25.0 \%$ to $31.4 \%(\mathrm{p}=0.048)$ Table 3 .

The average age for the 1966-1993 period was 57 years and for the 2000-2017 period it was 55 years. In the first, only $6.1 \%$ of the patients were 40 years old or younger compared to $9.5 \%$ of the patients in the second period $(p=0.095)$. Likewise, $19.0 \%$ of the patients from period 2000 to 2009 were 48 years old or younger compared to $28.0 \%$ of those in the period 2020 to $2017(\mathrm{p}=0.011)$ Table 4 .

Only in 874 cases did we obtain the histopathological varieties, $745(85.2 \%)$ corresponded to endometroid carcinomas (Type 1) and $129(14.7 \%)$ to non-endometroid carcinomas (Type 2) [1, 10].

CS was obtained in 898 patients. A ratio of 116 (48.7\%) patients in the first group was classified in stage I compared to $404(61.2 \%)$ of those in the second $(\mathrm{p}=0.001)$. We consider advanced neoplasm as CS II, III and IV, of these we added $378 / 898(42.0 \%)$ patients in the global series.

Of the patients classified in CS I from the period 2000 to $2009,113 / 147(84.0 \%)$ were diagnosed as overweight and obese. And of the stage I patients diagnosed between 2000 and 2017, 119/389 (30.5\%) had risk factors for tumor recurrence (Stages Ia: vascular infiltration and / or high degree of malignancy and stages Ib: myometrial infiltration equal to or more than $50 \%)[1,10,11]$.

Table 1. Endometrial cancer. Registered patients in 44 years.

\begin{tabular}{llll}
\hline Period & No. of years & No. Of patients & Significance \\
\hline (a).1966-1993 & 27 & 260 & $\mathrm{P}<0.05$ \\
(b).2000-2017 & 17 & 785 & \\
Total: & 44 & 1045 & \\
\hline
\end{tabular}

(a) vs (b): ( 9 cases vs 46 cases by year).

Table 2. Gynecological cancer. Relative frequency at different times.

\begin{tabular}{|c|c|c|c|c|c|c|c|}
\hline \multirow{2}{*}{ Neoplasm } & \multicolumn{2}{|c|}{ (I) 1983-1984 } & \multicolumn{2}{|c|}{ (II) 2010-2011 } & \multicolumn{2}{|c|}{ (III) 2016-2017 } & \multirow[t]{2}{*}{ Significance } \\
\hline & No. & $\%$ & No. & $\%$ & No. & $\%$ & \\
\hline 1. Cancer of cervix & 727 & 88.9 & 632 & 60.6 & 427 & 47.0 & I vs. II $\mathrm{p}<.05$ \\
\hline Corpus uterine cancer & 38 & 4.6 & 197 & 18.9 & 274 & 30.2 & I vs. II $\mathrm{p}<.05$ \\
\hline Epithelial ovarian cancer & 52 & 6.3 & 213 & 20.4 & 206 & 22.7 & I vs. II $\mathrm{p}<.05$ \\
\hline Total: & 817 & 99.8 & 1,042 & 99.9 & 907 & 99.9 & \\
\hline
\end{tabular}

1.(II) vs.(III) $\mathrm{p}<.05$ 2.(II) vs. (III) $\mathrm{p} .0001$ 3.(II) vs. (III) $\mathrm{p}=0.2245$.

Table 3. Risk Factors.

\begin{tabular}{|c|c|c|c|c|}
\hline \multirow{3}{*}{ Variable } & \multicolumn{4}{|c|}{ Period analyzed } \\
\hline & \multicolumn{2}{|l|}{ 1966-1993* } & \multicolumn{2}{|l|}{$2000-20017 * *$} \\
\hline & $\mathrm{N}^{0}$ of patients & $\%$ & $N^{0}$ of patients & $\%$ \\
\hline Obesity & 120 & 46.1 & (b) 572 & 72.5 \\
\hline Hypertension & 78 & 30.0 & (b) 260 & 33.0 \\
\hline Diabetes & 65 & 25.0 & (b) 248 & 31.4 \\
\hline Total: & 260 & & 785 & \\
\hline
\end{tabular}

*Average age: 57 years. **Average age: 55 years.

Significance: 1 (a) vs. (b) $\mathrm{p}<0.05,2$ (a) vs. (b) $\mathrm{p}=0.4123$ (a) vs. (b) $\mathrm{p}=0.048$. 
Table 4. Frequency in premenopausal patients.

\begin{tabular}{lllll}
\hline Age groups & Period & $\mathbf{N}^{\mathbf{0}}$ & $\mathbf{\%}$ & Significance \\
\hline \multirow{2}{*}{$<4$ years } & $1966-1993$ & $16 / 260$ & 6.1 & $\mathrm{P}=0.095$ \\
& $2000-2017$ & $69 / 723$ & 9.5 & \\
\multirow{2}{*}{48 years and $<$} & $2000-2009$ & $40 / 210$ & 19.0 & $\mathrm{P}=0.011$ \\
\hline
\end{tabular}

\section{Discussion}

The increase in the number of overweight and obesity documented in several countries after 1975 [15] was associated with a higher incidence of EC as in the USA [5]. This obesity epidemic has had a dramatic impact on public health. The average age of presentation of this disease is 60 years or more, but in overweight and obese patients it is less than 60 years $[5,15]$. In the authors series from the years 1966-1993, the average age was 57 years and $46.1 \%$ of the patients reported overweight and obesity [14], while for the age from 2000 to 2017, the average age was 55 years and $72.5 \%$ were overweight and obese $(p=<05)$. Up to $28 \%$ of the patients in this last series were premenopausal (48 years of age and younger).

The NSHN published in 2018 data on overweight and obesity registered in our country in the last 30 years with figures of $34.5 \%$ for $1988,61 \%$ for $1999,69.3 \%$ for 2006 , $71.2 \%$ for 2012 and $74.9 \%$ for 2018 [9]. In 2012, the figures for overweight and obesity for women were $73 \%$ and $76.8 \%$ for 2018 [9]. Figure 1 shows the correlation between overweight and obesity, with the increase in EC reported in our Unit for the intervals 1966-1993 and 2000-2017.

BMI is the main factor for predicting the risk of other chronic diseases such as diabetes and hypertension, conditions that influence the incidence and prognosis of EC $[1,5,6]$. These factors are currently present in $31.4 \%$ and $33 \%$ of the present study for the years 2000-2017 with statistically specific differences for the increase in diabetes in the period 2000-2017 $(\mathrm{p}=048)$.

Although more than $80 \%$ of endometroid EC are linked to overweight and obesity, current reports are also related to these risk factors with type 2 non-endometroid cancers whose prognosis is less favorable $[1,4]$.

The increase from $19 \%$ to $28 \%$ of $\mathrm{CE}$ cases in women younger than 48 years diagnosed in 2000-2009 vs 2010-2017 $(p=0.011)$ stands out, which $84 \%$ of those classified in Stage I of the 2000-2009 period, they were overweight and obese; that $30.5 \%$ of this last group had risk factors for tumor recurrence and that $42.0 \%$ of the overall series, had advanced malignancies $[1,10,11]$.

\section{Overweight / Obesity and Endometrial Cancer}

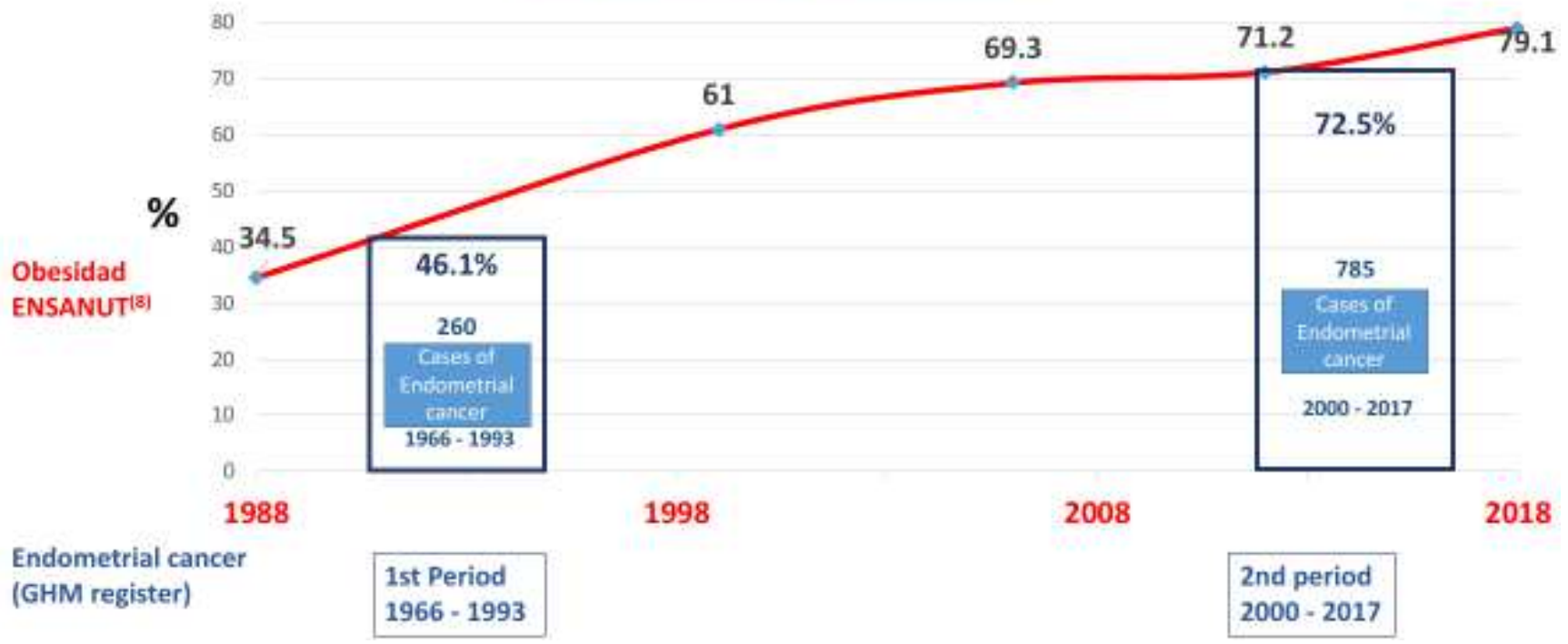

Figure 1. Correlation of overweight and obesity in Mexico from 1988 to 2018. Endometrial cancer in Mexico General Hospital in the periods 1966-1993 and 2000-2017.

\section{Conclusions}

In this series we find an increase in EC of $200 \%$ in relation to what was published in the previous study of our institution. For overweight and obesity, the figures rose from $46 \%$ to $72.5 \%$ ( $\mathrm{p}=0.05$ ). Likewise, an increase from $19 \%$ to $28 \%$ of EC was observed in women younger than 48 years $(\mathrm{p}=0.01)$. It was found that $30.5 \%$ of the patients with early stages of EC had risk factors for tumor recurrence and $42 \%$ 
of the overall series had advanced malignancies, which has affected their prognosis. The increase in overweight and obesity and in the EC figures reported in this series, may highlight the public health problem that this association is representing in our country.

\section{Conflict of Interests}

All the authors do not have any possible conflict of interest.

\section{References}

[1] Santaballa A, Matías-Guiu X, Redondo A, Caballo N, et al. SEOM clinical guidelines for endometrial cancer (2017). Clin and Translat Oncol 2018; 20: 29-37. doi: 10.1007/s12094-0171809-9.

[2] Cancer Facts and Figures. American Cancer Society. 2018. Pag. 4.

[3] Mexico. Source Globocan 2018. Number of new cases both sexes. International Agency for Research on Cancer. World Health Organization. 2018, p: 1-2.

[4] Fernández CSB, Leon AG, Herrera TMC, et al. Perfil Epidemiológico de los tumores Malignos en México. Dirección General de Epidemiología (SINAIS/SINAVE/DGE/Salud). México D. F. Secretaría de Salud; 2011. p. 46-122.

[5] Onstad AM, Schmandt ER, and Lu HK. Addressing de Role of Obesity. Endometrial Cancer Risk, Prevention, and treatment. J Clin Oncol. 2016; 34: 4225-4230. doi: 10.1200/JCO.2016.69.4638.

[6] Nevadunsky SN, Arsdale Va, Strickler DH, Moadel A, et al, Obesity and Age at Diagnosis of Endometrial Cancer. Obstet Gynecol. 2014; 124: 300-306. Doi: 10.1097/AOG.0000000000000381.
[7] Himbert C, Delphan M, Scherer D, Bowers WB, Stephen, and Cornelia M. Hursting C. Signals from the Adipose Microenvironment and the Obesity Cancer Link A Systematic Review. Cancer Prev Res. 2017; 10: 494-506. doi: 10.1158/1940-6207.CAPR-16-0322.

[8] Campos NI, Cuevas NL, González CLD, Hernández BL, et al. Epidemiología de la obesidad y sus principales comorbilidades en México. En: La Obesidad en México. Estado de la política pública y recomendaciones para su prevención y control. Editores: Juan Ángel Rivera Dommarco, Maranta Colchero y col. Instituto Nacional de Salud Pública. México 2018. p: 31-38.

[9] Encuesta Nacional de Salud y Nutrición 2018. Presentación de resultados.

ensanut.insp.mx $>$ informes $>$ ensanut 2018 presentacion_result ados. 2019: p. 41.

[10] Uterine Neoplasms. NCCN clinical Practice Guidelines in Oncology (NCCN Guidelines) 2019. Endo 4-10.

[11] Creasman TW, Scott MD. Adenocarcinoma of the Uterine Corpus. In: Clinical Gynecologic Oncology Eds. Philip P Disaia, William $T$ Creasman et al. Elsevier Ninth Ed. Philadelphia 2018. P. 131-135.

[12] Torres LA, Plata NP, Cruz TF, et al. Cáncer ginecológico, 1983-1984. Frecuencia relativa y resultados del tratamiento. Unidad de Oncología. Hospital General de México. Rev Med Hosp Gen (Mex) 1987; 50: 169-177.

[13] Torres LA, Amoretti C, Morgan OF. Cáncer ginecológico: evolución de su frecuencia relativa en una Institución de alta especialidad. Gac Mex Oncol (GAMO) 2014; 13: 222-228.

[14] Torres LA, Flores VA, Rojo HG, Román BE, et al. Cáncer del endometrio en el Hospital General de México: 27 años de experiencia. Rev Inst Nal Cancerol (Mex) 1998; 44: 124-133.

[15] Islami F, Torre AL, Drope MJ, Ward ME, et al. Gobal Cancer in Women: Cancer Control Priorities. Cancer Epidemiol Biomarkers Prev. 2017; 26: 458-70. doi: 10.1158/10559965.EPI-16-0871.

\section{Biography}

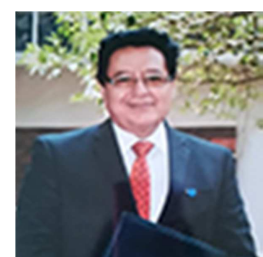

6.2004 .

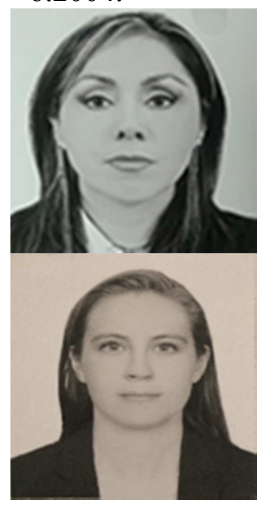

Alfonso Torres Lobaton: Founder of Oncology Gynecology Residence in Mexico and Professor of the Oncological Gynecology Specialty, Graduate Division of the National Autonomous University of Mexico School of Medicine. Emeritus Member of the Mexican Academy of Surgery, Full Member of the Mexican Society of Oncology, Former Head of Gynecology Oncology, Former Head and Technical Consultant of the Oncology Service Hospital General de México. Former president of the Mexican Council of Oncology. Author of 110 articles on cancer and 2 books on Gynecological Cancer: 1st. Ed Think ISBN 968-882-061-x, 2000 and 2nd. Ed. Mc Graw Hill ISBN 970-10-4376-

Rosalva Barra Martinez: Surgeon Oncologist, Master of Science, Full Member of the Mexican Society of Oncology. Associate Professor of the Specialties of Oncological Surgery and Oncological Gynecology. Graduate Division of the Faculty of Medicine of the National Autonomous University of Mexico, Tutor of 10 theses of the specialty and Author of 5 chapters of Oncology books and publication of 20 articles on cancer.

Elisa Paola Jimenez Arroyo: Gynaecological Oncologist who started her medical training in the Autonomous University of The State of Mexico. Afterwards, she made the Gynaecology and Obstetrics specialty and Oncoloical Gynaecology subspecialty at General Hospital of Mexico, with both degrees endorsed by National Autonomous University of Mexico. She has training in colposcopy, as well as minimal invasive surgery. She has participated in papers such as vulvar cancer surgery and its evolution in time, and the changes in epidemiology of gynaecological cancer in Mexico. 


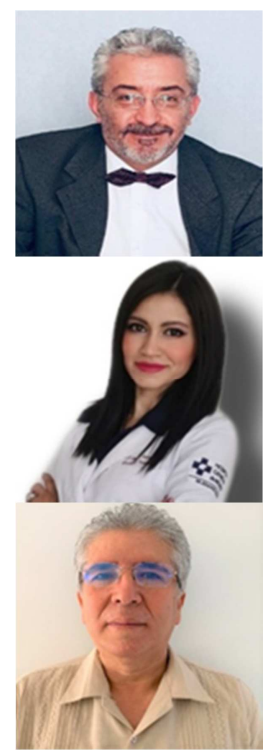

Juan Carlos Oliva Posada: General Surgeon and Oncologist Surgeon. Head of the Gynecological Tumors Unit in the Oncology Unit of the General Hospital of Mexico. Counselor of the Mexican Council of Oncology. Professor at Anahuac University in cancer biology course. Member of the National Unit of the Angeles group. He has participated in international papers of Vulvar, Endometrial and Cervical Cancer.

Carla America Suarez Juarez: Gynecological Oncologist who began her medical training at the La Salle Mexico School of Medicine, she completed the specialty of Gynecology and Obstetrics and the subspecialty of Oncological Gynecology at the General Hospital of Mexico. She is trained in colposcopy as well as minimally invasive surgery. He has participated in international papers of Vulvar, Endometrial and Cervical Cancer. She currently works at the Angeles Metropolitano Hospital, and his member of the Mexican Society of Oncology.

Fred Morgan Ortiz: Master of Science Gynecologist. Center for Research in Health Sciences. Autonomous University of Sinaloa, Mexico. Professor of the Specialty in Gynecology and Obstetrics, Autonomous University of Sinaloa. Member of the national system of researchers level I 2013-2016. Professor of Gynecological Laparoscopy Diplomas, Center for Research and Teaching in Health Sciences, Autonomous University of Sinaloa and the Civil Hospital of Culiacan. Director of 77 Specialty and Master theses. Publication of 97 articles on the specialty and Author of the book Laparoscopic Surgery Manual. Editorial UAS, ISBN: 978-970-660-229-9. Mexico, 2009. 